\title{
Intersecting Identities, Divergent Views: Interpreting the Experiences of Women \\ Politicians in the Pacific Islands
}

Jack Corbett, Griffith University

Asenati Liki, University of the South Pacific

\section{Abstract}

Anecdotally, it is assumed that the factors that constrain women from entering parliament spill over into the way they experience holding public office, thus limiting their influence. Drawing on in-depth biographical interviews and other publically available materials we test this supposition by investigating the experiences of women who have served in parliament in the Pacific Islands, a region famous for its low levels of women's representation. We ask if and how women see their gender as influencing their parliamentary roles. We identify two narratives. The first aligns with the orthodox assumption where prevailing patriarchal norms stymie the influence of women MPs. The second, however, is a counter-narrative that defies the conventional reading and instead posits that gender matters little once inside parliament with MPs highlighting the importance of other identities - family, community, religious etc. - to their constituent representation and re-election campaigns. In turn, women MPs who hold to this latter perspective are often critical of what they see as the imposition of gender norms by foreign donors. Employing the concept intersectionality allows us to simultaneously acknowledge and problematize this duality, thus providing a more nuanced reading of the impact of gender on parliamentary life in the Pacific region.

Keywords: intersectionality, Pacific Islands, women politicians, women's representation, interpretivism, gender and development. 


\section{Introduction}

Regularly labelled the worst region in the world in terms of women's representation in parliament, the Pacific has attracted increased scholarly attention over recent decades, especially as in some instances the number of women members is declining, defying conventional wisdom and the growing number of women holding senior positions in other sectors (Baker 2014; Fraenkel 2006; Huffer 2006). The relative absence of women members of parliament (MP) has also attracted significant donor interest, with numerous programmes designed to train female candidates. The rationale for increasing women's representation given by these agencies is twofold: 1) it is a fundamental human right; and 2) that women decision-makers are more likely to implement policies that benefit other women and their children. The Australian Government's aid program, the region's largest donor, outlines in its thematic gender strategy $(2011,11)$ how:

Working together, women can influence policies on gender equality and women's empowerment so other women benefit, and when women are politically active as voters or politicians, policies that improve the welfare of the nation are more likely to be implemented.

This rationale has underwritten numerous initiatives, including reserved seats for female politicians, support for which was enshrined in the 2012 Pacific Leaders Gender Equality Declaration (Pacific Islands Forum Secretariat 2012, 2; cf. Baker 2014). ${ }^{\mathrm{i}}$

In contrast, while there has been an increase in work seeking to understand the barriers that prevent women from holding public office, there has been relatively little attention given to the experiences of those that do; successful cases have tended to be overlooked. Typically, the unstated assumption is that the dynamics that prevent their participation - institutional factors (including access to land and titles), masculinist attitudes embedded in patriarchal cultures, stemming in part from colonial and mission influences, combined with the relatively 
low socio-economic status and educational access for women, despite universal franchise (for review see Huffer 2006) - continue to constrain their influence once in office.

In this article we test this view by asking how women experience holding public office in the Pacific Islands. We identify two divergent narratives. The first aligns with the orthodox assumption where prevailing patriarchal norms stymie the influence of women MPs. In this narrative, gender provides a powerful explanation for why the experience of women MPs differs from their male counterparts. The second, however, is a counter-narrative that defies the conventional feminist reading and instead posits that gender matters little once inside parliament. From this perspective, other identities, including those related to family, religion and social status, assume greater prominence and help these women make sense of why their experiences are often similar to male MPs. To interpret this duality we employ the concept "intersectionality" and argue that this theoretical lens provides for a more nuanced reading of gender and politics in the Pacific region.

To investigate the experiences of women MPs in the Pacific Islands, this article makes three moves: first, we outline our theoretical approach, data and methods; second, we provide a description of political life as seen by women MPs in the Pacific Islands. We investigate their reflections on campaigning and life in parliament, and outline how they negotiate family pressures and role expectations; and thirdly, we conclude by arguing that recognition of the intersecting identities of women MPs enables us to unpack the apparent contradiction between those who see their gender as central to their experiences and those who do not. The contribution of this article to the literature on women's representation in the Pacific stems from our exploration of the commonly overlooked views of sitting MPs about their roles, and the use of the concept intersectionality to do so. Practically, the lesson for women's rights advocates and other would-be-reformers in the Pacific, who may wish to claim women MPs as champions of their cause, is a cautionary one: not all women MPs want to be "poster 
girls" for this agenda. Theoretically the Pacific case adds to the literature on intersectionality by: 1) by paying particular attention to the importance of familial and kinship ties, rank, and religion to how women experience parliamentary life in the Pacific; and 2) highlighting how some women MPs associate attempts to increase women's parliamentary representation as foreign or imposed, and as a result downplay the intersection between their gender and political role.

\section{Intersectionality}

The concept 'intersectionality' first emerged in feminist legal scholarship and in particular Kimberlé Crenshaw's (1989; 1991) discussion of employment and gender violence amongst women of color in the United States. While her analysis focused on the intersection between race and gender, Crenshaw $(1991,1245)$ acknowledged that other "factors such as class or sexuality, are often as critical in shaping the experiences of women of color". Subsequently, "intersectionality" has been employed by feminist scholars across the social sciences to acknowledge and understand the complexities underpinning the articulation of women's experiences in various contexts (e.g. Alexander-Floyd, 2013; Hancock, 2007; Smooth, 2011). ${ }^{\text {ii }}$ In political science, the concept has commonly featured in analysis of women leaders. Louise Davidson-Schmich's $(2011,326)$ work on German Chancellor Angela Merkel, for example, noted:

A national leader's sex is only one of many characteristics he or she brings to national-level office. Merkel is not simply a female Chancellor, she is also an eastern, Protestant, scientifically-trained CDU Bundeskanzlerin. These characteristics have intersected, and she has backed policies which have benefitted certain German women more than others and pursued her own particular kind of female leadership style and foreign policy approach. 
While others (e.g. Von Wahl 2011; Yuval-Davis 2006) have shown that women, like men, belong to a variety of social groupings (ethnic, class, regional etc.) and may act as members of those groups rather than representatives of their gender and so "the identities of female leaders cannot be understood simply through a gendered lens but must include class, race, religion, sexual identity, etc. so that we can fully take account of the multifaceted intersection of differing oppressions and privileges" (Von Wahl 2011, 406). In response to the perpetual "who acts for women" question, intersectionality recognises the inevitable diversity of women and women's movements (e.g. Celis 2012), and the capacity for both men and women to promote women-friendly policy (e.g. Childs and Krook 2009; Curtin, 2008). As such, the concept and its emphasis on complexity and diversity has much to offer scholars of Pacific studies.

For gender scholars, the Pacific case is significant for a number of reasons, not the least of which is it's the stubbornly low levels of women's representation. As a consequence, donor governments and international organisations in particular have sought to promote greater representation via a variety of mechanisms that tend to be underpinned by a rights-based approach - that is, the fundamental right of women to be in parliament - that places gender at the centre of discussions about representation, to the exclusion of other factors. For example:

The charge for greater numbers of women in political leadership and national decision-making, stems from an understanding that equal participation is a basic human right and that sustainable development can only be assured with the equitable participation of all citizens in governance and national decision-making (UN Women 2013, 6).

As we shall see, some women MPs agree with this perspective whereas others, echoing the various critiques of so-called 'western' feminism by post-colonial scholars (most famously Mohanty 2003 but for the Pacific see also Marsh, 1998; Underhill-Sem, 2010), see it as an 
imposition that oppresses other aspects of their identity - family, culture and language group or religious and other community associations - that they see as important to both their sustained political success and sense of self. "Gender", from this perspective, becomes a negative term synonymous with other externally sponsored "good governance" interventions that seek to promote a particular form of democratic representation that these women see as antithetical to domestic political life - a view also shared by many men. Thus in the Pacific (and, we might infer, other aid recipient countries) "diversity" and "complexity" are not merely a reflection of the usual overlapping identities - gender, race, class and so forth - but are also bound up in the label "development" - what it means and how it should be achieved - with some women MPs preferencing the material well-being of their constituents over the advancement of other values, including gender.

\section{Data and Method}

In this article we use "Pacific Islands" as an umbrella term to capture interviews and other published English language material, including autobiographies and biographies, with politicians from Kiribati (5), Fiji (4), Samoa (4), Marshall Islands (2), Cook Islands (2), the Commonwealth of Northern Mariana Islands (CNMI) (2), Solomon Islands (1), Tonga (1), Tuvalu (1), Niue (1), Guam (1), and Palau (1). ${ }^{\text {iii }}$ Three women parliamentarians from PNG have written autobiographies including Dame Alice Wadega (1981), Dame Josephine Abaijah (1991), and Dame Carol Kidu (2002) while Tonga's Queen Salote has two biographies (Hixon 2000; Wood-Ellem 1999) and there is also a short reflective piece on Solomon Islands Hilda Kari in the book Being The First (Pollard and Waring 2009).

The focus on a specific region draws from the logic of area studies. The promise of area studies, as opposed to a single country study, or surveys of larger numbers of countries, is that shared history, geography, languages and religion are likely to affect the pattern of politics in similar ways (Larmour 2012,7). The choice of area studies is especially pertinent 
in the context of women's representation in the Pacific Islands as their relative absence from parliament is a shared phenomenon; most countries have only one or two sitting women MPs while the Federated States of Micronesia have had no female politicians at all.

Due to the scope of the material, and the assurances we gave to interviewees that we would not use names in any publications and as far as possible supress their identity, it has not always been possible to draw out specific comparisons between countries and institutional types; the plurality of which is a distinguishing feature of the Pacific region. ${ }^{\text {iv }}$ Where possible, we have used public comments to develop comparative themes, but in most cases we have sought to demonstrate similarities rather than differences. Accordingly, we do not deny temporal and spatial variances in how the institution of leadership is experienced by MPs across the Pacific, but have instead primarily chosen to focus on likenesses. In doing so we echo Epeli Hau'ofa's $(1987,3)$ description of growing similarity amongst the region's political classes, including a shared regional culture (synonymous with terms like the "Pacific Way”), language (English), ideologies (development) and material lifestyles (urbanised). Moreover, while Hau'ofa's view of this "new Pacific society” provides a theoretical justification for treating the region as a single entity, our emphasis on similarities is also informed by a belief that despite contextual differences, human impulses relating to power are in many respects shared by the people who pursue public office across the world. Consequently, while our main aim has been to provide an account that women politicians in the Pacific would see as authentic, we anticipate that their reflections will resonate with a more general audience.

In line with the conventions of interpretive research, the empirical material presented here has been developed both deductively and inductively (Yanow 2007). Our objective is to provide enough information for the reader to feel convinced that we are depicting the shared experience of political people rather than finding information to support a specific hypothesis 
and as such we employ extensive quotations to provide a sense of the politicians' voice (Reeher 2006, 23). However, this voice is ultimately constructed by us and as such represents patterns that we have identified as emerging from the collected data. While we have removed references that may easily identify the respondent, including country of origin in some cases, quotes have primarily been selected on the basis of their succinctness and were chosen from a series of responses that demonstrated a similar point; in most cases each quote could have been substituted for several others.

\section{Deciding to Run}

Women draw on multiple and overlapping aspects of their life stories to explain their decision to seek public office. Amongst those women politicians who do choose to run, all claim to do so because they want to make a difference (UNIFEM 1998), even if they enter reluctantly at the behest of others. As we shall see, the traditional link to political families is part of this rationale, as is increasing encouragement from the community (including women's groups and international organisations), but in their reflections MPs also recount policy concerns encountered during their professional or personal experiences, for example:

I was a journalist, I was [on] radio and TV for twelve years covering Guam, the CNMI and Micronesia ... So, I would follow the issues ... and I started to feel like a backseat driver "why did they do that? They didn't have enough information to make that decision”... So, yeah, I just felt that what I could bring to it was a seriousness. I would not be cavalier about it and I always made a point, later on as I became a lawmaker, I knew exactly why I did everything.

Similarly, Claire Baiteke of Kiribati recalls that what motivated her to run in the 1998 elections was her anger at a decision by the then all-male government to send I-Kiribati women to Hong Kong as domestic servants (UNIFEM 1998, 17). For Fepuleai Logo of Samoa, her resolution to run in the 2006 elections was influenced by the support of her 
family chiefs but also a desire to address land issues affecting her village and constituency (pers. comm. 2010). While the range of policy issues that women MPs have an interest in is too diverse to exhaust here, the reasons given by those who have run, as opposed to those who decided not to, are not markedly distinct from those given by male MPs (Corbett forthcoming).

Despite family support at home, many women politicians argue that they only started to consider running once their children were older:

I was just turning over 50 and that was a good time for me. Anything younger and I don't know. I would have had a very young family. But after fifty ... I think it's a good period and to really focus and be committed to a job as a politician.

[Samoan politician]

Women entering politics at an older age compared to men is a global trend. In the Pacific, women MPs mainly constitute those who either have grown up children or have never been married. One common explanation for the low number of female candidates elsewhere in the world is that the "eligibility pool" of usually established female lawyers and business executives, which are the leading occupations preceding a career in politics, is low (Fox et al. 2001). This view, however, is not true for the Pacific where women of different professions and with various local patronages/identities have entered parliaments. Rather, many qualified women prefer not to run.

Confronting and dealing with gender stereotypes before entering parliament is common among women politicians the world over. In the Pacific, external constraints such as lack of financial resources, family pressure and prevailing societal views favour male candidates (Brody 2009; Huffer 2006; Whittington et al. 2006) and contribute to what Nandini Deo $(2012,46)$ describes as women "running from" rather than "running for" elections. There is, for example, a relatively large number of women in senior positions in the public service - 
the most common recruiting ground for politicians in the Pacific - who do not see politics as a desirable career option (Liki 2010). Having to work for and deal with government ministers may have given them a less attractive picture of being in parliament. As one senior female manager in the Solomon Islands put it "I am not corrupt enough to be a politician". Others have been privy to the pressure placed on parents and close family during their political careers and so are reluctant to run:

[Father said] "you should be a Senator and take on my position". And being a smart-aleck young girl who just came back from school I said ... "I don't want to be like you, I want to enjoy my life." [Marshallese politician]

\section{Profile and Campaigning}

It is one thing to decide to run for office but quite another to win election and therefore as a prelude to discussing how women politicians in the Pacific Islands experience political life, it is important that we establish a profile of just who we are talking about. The profile of female politicians is central to the research agenda on intersectionality as it both provides a sense of where women have come from but also helps us understand where their political aspirations and affiliations lie. Profile is also an increasingly prominent question among donors seeking to identify and support "winners", and many of the women we interviewed had been supported at some stage along their journey by donor-funded initiatives.

\section{Families matter}

Historically, many Pacific women MPs come from "political families" and it has been this connection that facilitated their entry into the national legislature. PNG's Dame Carol Kidu (Johnstone and Powels 2012, 284), who is an Australian by birth, refers to the "sympathy vote" gained through her late husband that led to her winning the elections in 1997 - the term is common across the region. The Pacific's longest serving women MP, Samoa's Fiame Naomi Mata'afa, is the daughter of the country's first Prime Minister, a niece of the former 
Head of State, Malietoa Tanumafili II and has had uncles and aunties who were prominent MPs. This trend echoes the experiences of women MPs in other parts of the world, particularly Latin America and Asia, where a pattern of widows or children of former politicians succeeding them in elections has been dominant (Escobar-Lemmon and TaylorRobinson 2005; Wängrud 2009; Rai 2012). That is not to say that family connections guarantee successive election victory. As Deo $(2012,59)$ notes with reference to Indian politics "the first election victory may be chalked up to family connections, but family is rarely a good enough reason for voters to keep a politician in office if he or she is not delivering on campaign promises." This is certainly also true in the Pacific.

Ron Crocombe $(2008,468)$ argues that those women from the region who have succeeded in politics generally have powerful fathers or brothers, often foreign husbands, few children and a high level of education - usually from overseas (see also Corbett and Wood 2013).

Certainly many female politicians admit that they are often elected on the basis of their husband or father's profile. Hon. Vika Lusibaea, a women who was born in Fiji, is the second ever women to be elected to parliament in Solomon Islands. She won a bi-election after her husband, the sitting member and former militant Jimmy Lusibaea, was barred from office. ${ }^{\mathrm{v}}$ In cases where female politicians have foreign husbands - the first three women parliamentarians in PNG had expatriate partners, while the fourth, Dame Carol, was born in Australia - some admit that this is a source of greater personal support and freedom, whilst also presenting political limitations, as former Vice President of Palau, Sandra Pierantozzi (Johnstone and Powels 2012), summarises:

He's [husband] been a big support in my life. On the other side, politics in Palau is still a family affair, so where my opponent would lean on his father's relatives and his mother's relatives, and his wife's relatives on both sides, I cannot do that. It's only one way. 
Spousal support, however, and in particular their kinship links, is also of great importance to male politicians who often lean on their wife's relatives for votes, just as others have powerful patrons and mentors. Intuitively, due to their relatively weaker financial position, we might hypothesise that these relationships are more important for women, but this correlation is difficult to substantiate. Moreover, in some cases, like that of Selina MetengaNapa of Cook Islands, who ran and won against her brother, women MPs defy these stereotypes altogether.

\section{Education and career matters}

A civil service background is the most common pre-political career in the Pacific Islands and women MPs are no exception, although, Crocombe $(2008,468)$ argues that most come from the "caring" professions: nursing and teaching. In their study of pathways into UK politics, Durose et al. (2013) call this phenomenon "acceptable difference"; aspiring candidates from under-represented groups conform to aspects of the "archetypal candidate". Echoing this, while Crocombe's description is anecdotally accurate, we believe it loosely fits nearly all politicians who tend to be moneyed elites with overseas education (see also Corbett and Wood 2013; Corbett forthcoming). Indeed, aside from being relatively uncommon, our material suggests that there is no major discernible difference between the education and career backgrounds of women politicians and their male counterparts. Similarly, while first time electoral defeat is the most common story amongst women MPs, this is also true of male MPs even if, anecdotally, we suspect that this experience is relatively more common to women as many do not have the same level of financial clout.

\section{Rank matters}

Echoing Marshall Sahlins' (1963) famous “big-man-chief” taxonomy, one of the other anecdotal claims about the origins of female leaders in the Pacific is that it is easier for women to get elected in those countries where hereditary and rank were traditionally 
emphasised. Some of the women we interviewed believed that rank or title can reduce gender discrimination, as the following extract highlights:

The good thing about being a matai [chief], a women matai in the Samoan system, I felt that the men didn't really consider me as a woman but more as a fellow matai. I liked that. [Samoan politician]

However, this relationship is not always straight forward, as Fiame Naomi Mata'afa outlined in a radio interview with Ian Johnstone (Johnstone and Powels 2012), while a title can enhance a prospective politician's profile and reputation, access is still not always equal:

[Fiame] I was told, not formally, they didn't write it down on a piece of paper, but they said, "Listen kiddo, if you want to keep your title, you better stay put and look like you're serious about it." Which was quite unfair because other people were getting their titles and going off and doing other things.

[Johnstone] Would that have happened had you been a man?

[Fiame] Probably not!

Expectations relating to both gender and rank are implicated in this explanation, along with the legacy of Fiame's father. Similarly, one of the region's most celebrated female political leaders, Tonga's Queen Salote Malfile'o Piloevu Tupou III, had to ward off a series of rivals when she took the Tongan throne in her late teens. Her biographer, Elizabeth Wood-Ellem (1999), describes her early period in power as a series of tactical manoeuvres designed to strengthen what was perceived to be a weak and tenuous position. Consequently, while we can infer that heredity rank may have some influence on the pathways women take into politics, variations exist across the region and the assumption that it automatically correlates with higher female representation is challenged by both individual cases and general trends, with the number of women elected to parliament in PNG, a country usually associated with the absence of rank, 
rising from one to three at the 2012 election, compared with the 2011 Samoan election where the number dropped from four to two despite rank remaining a persistent feature of political life.

\section{Community matters}

Religious aspects of community involvement for politicians have been well-documented elsewhere (see Corbett 2013) and so we will not rehash them here at length. The important point is that church-based institutions are at the centre of community life in the Pacific and so nearly all politicians, male and female, are heavily involved in these activities. Religious association can matter much more than political parties, for example. ${ }^{\mathrm{vi}}$ In the relative absence of bureaucratised political parties, candidate screening occurs via other means, as Dame Carol Kidu outlines in an interview with Ian Johnstone (Johnstone and Powels 2012):

Of course when I stood I went through all the cultural hoops, I asked family permission, I asked an elder first that I thought would be sympathetic, then we asked the immediate family, then we asked the clan, after we asked the immediate family we went to Buri's [husband] grave and the elders spoke to Buri and said "this is what's going to happen, please help her and support her." Then we went to the clan and so on. Any woman who's going to go must go through those cultural hurdles.

Some women feel that campaign conventions limit their choice of campaign style; particularly the late nights, the growing costs, and the alcohol and kava routine:

So, when I went around campaigning and you come up against obstacles. "What can you as a woman do?" You know. They say "your place is in the kitchen" and I said "hey give me a chance to run, give me an opportunity to prove that I am just as capable of being able to do things the same as the male species." It was full on. 
[This Cooks Islands politician won the election]

Others contend that a common barrier is the popular belief that politics is corrupt, and that to be an influential politician you have to be under-handed, and some women feel that it is hard to portray an image that is tough enough. Conversely, PNG politician, Dame Josephine Abaijah $(1991,306)$ recalls being put on a pedestal because she was a woman, and therefore beyond the corruption that afflicted men.

Importantly, most of those women who do run acknowledge that women's rights are not something that their constituents - male or female - care too much about: they want to see their MP provide basic goods and service, including better health care, education facilities, and infrastructure (roads, sea walls etc.). In Fiji's upcoming elections September 2014, two women candidates: feminist politician Roshika Deo, and labour candidate Mere Samisoni are focusing their campaign on youth unemployment, poverty, education, small business development, and religious freedom as priority areas (Swami 2014). A linear modernisation narrative might expect that this view would be declining in light of the global gender movement. However, this trend is also common amongst many so-called "new generation" women MPs (newly elected women from PNG, Cook Islands, Tuvalu and Nauru, for example who are not necessarily feminists in terms of their ideology or electoral appeal).

Theoretically, the important point is that a focus on the ways identities intersect allows us to understand why there are similarities in the stories that both men and women tell about their entry into parliament, and help us to explain how gender can both empower, as in the case of Abaijah, and constrain candidates.

\section{In Parliament}

I had no great ambition to become a politician. It was more a challenge to be elected desire than a desire to play the game. It was a desire to achieve the 'impossible' and to prove the colonials wrong that drove me to do something that 
I had little heart for. Perhaps I wanted to repeat a long colonial experience of being the first: this time, the first women to be elected to Parliament. It was excessively easy to be a first in colonial Papua (Abaijah 1991, 172).

The parliamentary experiences of women MPs are a mixture of excitement and frustration. Women MPs face all kinds of challenges, some of which relate to their gender. Due to their relative absence from the legislature, it should come as no surprise that one experience female politicians' commonly share is a sense of their own uniqueness. Not only are they often perceived as a proxy representative for the silent majority, but in many cases they are "firsts": the first women to be elected from their family, community, constituency or country; or the first women to become a minister, opposition leader, or in the case of Pierantozzi and Teima Onorio of Kiribati, vice-president. Only one of the interviews that we conducted was with a politician who had won a constituency seat previously held by a woman; a legacy that she believed made her candidature easier. Consequently, women politicians in the Pacific Islands are often seen as pioneers - something that is often a source of great pride - but as a result their experience of serving is often associated with loneliness:

The way I look at myself as a women in politics, it is very challenging ... as a women it is very difficult, in terms of dealing with these male politicians ... and I am the only female ... so many times I wish there was another women there ... it's hard.

[This politician also expressed great joy at the impact of her work, and had aspirations to run for higher office in coming elections]

Recently elected PNG MP, Hon. Loujaya Toni told her supporters: "My journey is one I must make alone in a house of many divides" (Jackson 2012). Or, as one Tongan MP put it: "The Tongan parliament is not women friendly" (Durutalo 2012, 30). 
While this sense of isolation is a strong theme, being in the minority also presents other difficulties. Some women believe that they are disproportionately the targets of gossip and malicious rumours:

When two persons [get pregnant] ... it is always the girl that gets the blame ... It is tough for women. It always easier for anybody to blame the women and make gossips and lies on that woman, and they believe it ... [Marshallese politician]

The negative and stereotypical views of male politicians can also be discouraging. During debate about reserved seats for women in Samoa, a male MP's comment that such seats were afa pusi (not full able-bodied cats, implying a lower status of such seats in parliament) was challenged by the two women MPs and some women's groups on the grounds that it was derogatory. Dame Carol Kidu reflected that the negativism of so many male colleagues inspired her to keep going (Johnstone and Powels 2012). For others, exclusion can be more frustrating than slander:

One of the things that I always think about is that when you are in an area of work you usually find your friends there. Well I have to say I haven't found my friends in politics and part of that is because of the gender thing. Being female and not being married, because you just have to be so careful about those sorts of things ... For a number of years there they would never take me on any of their trips ... they didn't want me tagging along, their wives wouldn't like it, I would get in the way. It was just too hard so they didn't go there ... the public works guys didn't want me and of course they gave someone else the women's stuff, then that minister didn't particularly want a young woman sort of underfoot, that sort of thing.

[Despite these experiences, this politician spent more than two decades in parliament, predominantly in ministerial positions] 
Such discrimination is by no means confined to politics in the island Pacific. In neighbouring Australia, the gender of its first female Prime Minister, Julia Gillard, attracted sustained controversy (for discussion see Sawer 2013). In contrast, former NZ Prime Minister Helen Clark “actively carried her reputation as a supporter of women's issues and indigenous politics with her into the top job" (Simms 2008, 34). In such cases, differences can be attributed to both individual style and prevailing cultural attitudes, or the combination of both, and the Pacific is no different.

Many see their primary contribution as paving the way for other women leaders:

... it is getting a little bit easier for women. I think what I see as part of my responsibility is to demonstrate to the women here what is possible. You don't have to be a millionaire, you don't have to be married, you don't have to be slim and thin. You just have to think and be coherent and look after the interests of the people. [Palauan politician]

However, while some level of discrimination - either implicit or explicit - is a commonly expressed sentiment, it is also true that some female politicians deny that gender has any impact on their role within the legislature:

I didn't see it as an issue and neither did the other lady members of the house. Niue women, we don't see ourselves as victims of this whole gender inequality thing ... When we do make decisions in the house, if anything, it is always in favour of women. The men folk are the ones questioning "Hang on a minute, how about us.” Yeah, a non-issue. [Niuean politician]

Others, particularly from matrilineal societies, point to culturally mandated gender roles, often emphasising complimentarian ideals, as Pierantozzi (Johnstone and Powels 2012) asserts: 
When I was growing up I came from a culture, a matrilineal culture, but I didn't feel really oppressed per se, but I knew that I had roles and that I'm a woman, and there are certain roles I have to play.

But culturally speaking, Palauan women like to sit in the back and control things ... You come to Palau at any campaign time, it's the women that are going house to house knocking on doors campaigning for their husbands, their uncles, their brothers. The men sit at home.

For these women, the prevailing wisdom that women MPs are marginalised or disempowered is misleading; it demeans both them and their male colleagues.

\section{Family Pressures}

Most of my male colleagues had wives who were devoted to supporting them ... it is not the same with a women who works. I mean, even though everybody is saying there is equality, you still do those things that come naturally to you. Like, scream at the kids and tidy up after them, do the washing ... I think it doesn't come naturally to men yet, to automatically support their wives when they are in public office.

[This politician was the first woman to hold a ministerial portfolio in her country]

The idea of a "double burden" for women who work is a well-documented phenomenon that sociologists have identified throughout the world and so it is perhaps no surprise that many female politicians in the Pacific Islands worry about the impact of their political involvement on their children in particular:

The negative part of it is that I was away from my children, you know, the whole time, and my family sacrificed a lot. But, at least we were able to, we learnt how to cope with it, it was also a learning experience for the children and I will not be surprised if they will participate [in politics] themselves. Especially my daughters 
they are very strong, and very responsible and determined. [Marshallese politician]

On the other hand, while absence from family is a commonly cited concern for women members, former Cabinet Minister in PNG, Nahau Rooney, argues that traditional family structures make it easier for female politicians as the extended family is able to assist with domestic and maternal duties (Dickson-Waiko 1999, 104). Similarly, for every example of absence, others argue that husbands and partners have provided invaluable support at home:

It has changed our life. Mine and my husband's role has slightly changed. He has taken over looking after the kids at home, making sure their homework is done at night [and] dinner is cooked because sometimes I am just off busy and that. And he has been so wonderful in helping, I have been worried about that. The male perception: "this is not my job, this is a women's job." But he has been really good. [Cook Islands politician]

Despite this actuality, many politicians express a sense of guilt at the impact of their political work on family life:

I admit that I did not give my family that fair amount - mainly because I am here for the whole day, and when I travel for ministerial meetings and all of those ... Because they have been supportive, that's why I don't notice it. But to be honest, I haven't had fair time with my family. Particularly, my children and grandchildren. [Samoan politician]

Although, again it is important to note that male politicians express similar sentiment. Indeed, it is not uncommon for politicians to concede that if they had known the cost of their political career on their families from the beginning, they would not have run for office. 


\section{Women Politicians and Performance}

Performance in parliament and dealing with community expectations of their multiple roles and identities as female leaders loom large in the reflections of women MPs about parliamentary life. Solomon Islands first female MP, Hilda Kari $(1995,4)$, referred to herself as "a woman of the people" and was always conscious of her identities "as a woman, a wife, and a mother who also ha[d] a higher national calling as a politician."

Most of the time, my residence is full. My telephone is a hot line. Most requests are for financial assistance. There is the need to transport a dead body home; the need to order coffins. Some even ask me to help buy nappies, school fees, feed those who have been hospitalised. Besides that, there are requests for chainsaws, fibre-glass canoes, outboard engines, water tanks, materials for church buildings, goods for retail and wholesale stores. Without exception, there are even requests for kitchen utensils such as cups, plates and spoons. This is difficult to end or even to imagine that it is ever complete (Kari 1995, 7).

Being critical of these expectations, yet simultaneously yielding to them, defines the ways MPs, both men and women, negotiate their roles.

Most politicians relate that gaining the respect of their fellow MPs is an important part of their socialisation into parliament. However, female politicians in the Pacific Islands tend to also talk about how they feel the need to work harder than their male colleagues to gain this status; they have to prove that they are capable of contributing, not only to their fellow parliamentarians but to the public:

When I became a Senator in Guam ... [it] meant that I was going to get the Presidency [of a regional organisation], and they weren't having it ... they didn't want a women as the President ... And what happened when I got voted in half of 
the delegates, half of the people were out of the room because they didn't want to raise their hand to me.

So, this is the best part, I became President, and I was so serious. I did so much work. I was so conscientious ... [and] I became the first one they gave a second term to. The second time, just one year later, everybody was in the room and they gave me a standing ovation, unanimous applause. It was hard at first but what happens when you are a women, you are just used to it [Guamanian politician]

Not that all women experience this type of performance anxiety, just as most argue that they are more than capable of defending themselves against discrimination and sexism. Indeed, many are quick to highlight that the legislature can be more willing to embrace female politicians than the electorate:

I mean, you do get challenged but if you know how to handle it, it wouldn't be any different. I mean you will always be challenged in the beginning as a woman because we are always supposed to be the weaker side. But, you know, if you know your job then they [colleagues] will respect you ... I don't really have any strong feelings that, you know, my being a women [in parliament] makes any difference. [Samoan politician]

One of the main justifications articulated by women politicians in the Pacific Islands for equal representation is the strong belief that women are different legislators to men; that they not only bring a different perspective, but also a new, more feminine, approach to decisionmaking that emphasises compassion over ego, and is less susceptible to abusing executive power and other practises often described as corrupt. Certainly, some women MPs feel that constituents seek them out due to their gender:

The ladies especially, they feel free talking to a woman instead of a man ... I say “hey, why don't you go and see your [member]?" And they say "no we want to 
come and see you, especially on ladies issues, it is not comfortable for us, we can't talk freely."

[I-Kiribati politician]

However, while women politicians may resist corruption in instances where it is stigmatised (Esarey and Chirillio, 2013), there are also examples that contradict this popular image of incorruptibility with Nahau Rooney, for instance, sentenced to prison in the 1980s for interfering in a deportation case, now commonly known as the "Rooney Affair" (DicksonWaiko 1999, 102). Nevertheless, the narrative retains currency with women leaders across the Pacific and is an often cited justification for why there should be more women in parliament, which tends to be linked to how they see their traditional role as peacemakers. The role of women as peacemakers has particular significance in Bougainville, the one political entity in the Pacific with reserved seats for women, but this theme is also common to other parts of the region:

... at times it can be like boys little fights, but I am caught in the middle of it ... I hated myself, I really did hate myself ... it [vote-of-no-confidence] compromised my principles as a women. Traditionally women are supposed to keep the peace [so] it really compromised my whole being. I hated it and I didn't forgive myself for a long time. [Marshallese politician]

Evaluation of MP performance is most commonly tested during elections. Some losing MPs believe that their gender is a contributing factor:

[Author] Would you run again?

Probably not, I don't think the people are ready to vote women in and I think what I am doing out there in the private sector is more effective in being able to just speak freely about issues and take up politicians on things they do. [former Tongan minister] 
This is particularly true of those women who were initially elected on the back of a "sympathy vote" - they won the bi-election after their husband or father, who was the sitting member, passed away. Voter expectations are also changing. While traditional alliances persist, they combine with newer realities, including the expectation that MPs will deliver material benefits to electors, to alter voting behaviour. However, in all cases there are exceptions. As we have highlighted, some women spend decades in parliaments just as others, who initially received a "sympathy vote", now stand on the strength of their own achievements and personal popularity.

\section{Conclusion: Dualism or Duality?}

This article has intentionally focused on the gendered nature of parliamentary practice in the Pacific but what emerges from the stories that women politicians tell about parliamentary life is a strong sense that gender is rarely the only variable at play, either during elections or in the chamber. Women MPs believe that issues pertaining to gender relations and women's human rights are not at the forefront of campaign agendas, nor, for the most part, do they consider that voters perceive their gender as positively impacting on their candidature. Instead, they focus, both during campaigns and in their parliamentary work, on "substantive" issues that are paramount to their electorates: poverty, education, health services, violence against women and children, small business development and land rights. This tends to parallel experiences in some African countries where women MPs push for appropriate legislations relating to more pressing issues such as land rights, poverty alleviation, HIV/AIDS, and gender violence (Devlin and Elgie 2008).

Flagging broader issues while simultaneously downplaying the influence of their gender is a common strategy adopted by women leaders the world over. Referring to women in European parliaments in the 1970s and 1980s, Ribberink (2010, 5-6) notes that "Being tough as a female politician meant, among other things, to avoid 'women's issues', such as health, social 
work and legislative emancipation". Intersectionality provides us with a conceptual lens through which to understand these dynamics. In particular, it helps us unpack the apparent contradiction in women's experiences of political life in the Pacific Islands where two distinct narratives about the importance of gender are at play. The first falls in line with the orthodox assumption where prevailing patriarchal norms stymie the influence of women MPs. As we saw, some women MPs believe that campaign norms, parliamentary standards and family pressures limit them relative to their male counterparts. In most cases, this narrative identifies prevailing "patriarchal culture" as the primary culprit:

Customs and traditions are very strong. The norms are very strong ... in our custom women are not allowed to raise their voices in the meeting halls. But I think nowadays, as I can see now ... it is changing. If I went back to my constituency and were to work hard to give them some awareness, work with them, mostly the women's community, I think they really can support me. But I have to do my best and work hard for them because it is good for my constituency. [This politician is the only female MP in parliament]

The second, however, is a counter-narrative that defies the conventional feminist reading common to donor manifestos and instead posits that gender matters little once women are elected to parliament. As we saw, for these women the experience of being an MP is not vastly different from their male colleagues. As the above extract highlights, one interpretation of this description is dualism: existing norms and values are being challenged by externally sponsored "good governance" interventions that seek to promote a particular form of democratic representation which aims to provide greater scope for women to participate in the public sphere. However, as we saw, it is also true that appeals to tradition and culture are central to the rise of some women as political representatives, while others draw on this language to critique what they see as external interference by foreign donors. 
In problematizing the idea that tradition is being replaced by modernity, we understand these experiences as a duality; they coexist. Recognising the duality of how women MPs in the Pacific experience their political roles helps us to understand why some MPs support orthodox feminist perspectives, including gender quotes and reserved seats for women, whilst others are often critical of would-be-reformers and the way donors in particular push a feminist agenda (see also Baker 2014). These women push back against the negative view of the Pacific as "the worst" in terms women's representation, for example, and claim that rather than "empowering" them, donors make being a women MP harder by constantly seeking them out for speaking engagements at regional meetings and workshops, thus limiting the time with which they can work for their constituents. Indeed, some confess to being bullied at these events to advocate for a feminist cause. In contrast, these women MPs align themselves with more "conservative" ideas and values, including those espoused by certain churches.

Of course, the fact that not all women politicians are feminists is not unique to the Pacific. What is distinctive to aid recipient countries, however, is the asymmetry some women experience in their dealings with donors in particular. In contrast to their candidness about the negligible impact gender had on their experience of holding public office, we found these same politicians less willing to vocalise critical views of donor gender initiatives "on the record", despite the promise of anonymity; many were very happy to talk at length once the microphone was turned off. In part, we can infer, this is because development is big business in the Pacific and for many careers and electorates are dependent on donor attention.

Nevertheless, the existence of these critical views, and the manner in which they are shared, need to be incorporated into our understandings of the ways gender and politics interact, both within the Pacific and on other aid recipient countries.

The lesson for the literature on intersectionality is that in addition to the usual factors - race, class, career etc. - that we have demonstrated shape how women experience the political 
sphere, in the Pacific some women actively resist what they see as the imposition of gender norms from outside. In doing so, they can draw on the language of culture and tradition, often mediated by Christian ethics, to explain their opposition. Rather than one replacing the other, our material allows us to both account for these divergent views by showing how they are mirrored in the experiences of those who run for office - i.e. some think gender matters and others do not - while simultaneously illustrating that this simple "insider-outsider" depiction belies the complexity of everyday political life.

Although beyond our scope here, highlighting how women MPs employ these two narratives at different times and in different contexts is an important next step to further this research agenda. Certainly, our research hints at the extent to which context - be it cultural, institutional or temporal - matters to the ways these narratives manifest in and transform public debate about gender in the region. Our data, by virtue of its small size, cannot speak to these comparative themes in a rigorous fashion. Rather, our more modest and fundamental point is to call for greater recognition that these narratives coexist, that they have deep roots in the intersecting identities of women MPs, and as such inform the way they think about the gendered nature of the public sphere and act within it. Ultimately, while not all women MPs hold to these critical views, either in public or private, recognition of this duality provides for a more nuanced reading of the impact of gender on politics and parliamentary life in the Pacific, and therefore must be understood by all donors and would-be-reformers of politics and political institutions.

\section{Bibliography}

Abaijah, Josephine. 1991. A Thousand Coloured Dreams: The Story of a Young Girl growing up in Papua. Melbourne: Dellasta Pacific.

Australian Agency for International Development. 2011. Promoting opportunities for all: Gender equality and women's empowerment: 
http://aid.dfat.gov.au/aidissues/Documents/thematic-strategies/gender-equalitystrategy.pdf (November 29, 2013).

Alexander-Floyd, Nikol. G. 2013. “(Inter) disciplinary Trouble: Intersectionality, Narrative Analysis, and the Making of a New Political Science”. Politics \& Gender, 9(4): 470474.

Baker, Kerryn. 2014. "Explaining the outcome of gender quota campaigns in Samoa and Papua New Guinea.” Political Science 66 (1): 63-83

Brody, Alyson. 2009. “Gender and Governance - Overview Report”. BRIDGE Development - Gender. Brighton: Institute of Development Studies, University of Sussex. www.bridge.ids.ac.uk/reports/Governance OR final.doc (December 12, 2013).

Celis, Karen. 2012. "On Substantive Representation, Diversity, and Responsiveness." Politics \& Gender 8(4): 524-29

Childs, Sarah, and Mona Lena Krook. "Analysing Women's Substantive Representation: From Critical Mass to Critical Actors." Government and Opposition 44 (2): 125-45

Corbett, Jack. 2013. "'A Calling From God': Politicians and Religiosity in the Pacific Islands." Global Change, Peace and Security 25 (3): 283-297.

Corbett, Jack. Forthcoming. Being Political: Leadership and Democracy in the Pacific Islands. Honolulu: University of Hawaii Press.

Corbett, Jack and Terence Wood. 2013. "Profiling Politicians in Solomon Islands:

Professionalisation of a Political Elite?" Australian Journal of Political Science 48(3): $320-334$.

Crenshaw, Kimberle. 1989. Demarginalizing the Intersection of Race and Sex: A Black Feminist Critique of Antidiscrimination Doctrine, Feminist Theory and Antiracist Politics, University of Chicago Legal Forum:138-67 
Crenshaw, Kimberle. 1991. Mapping the Margins: Intersectionality, Identity Politics, and Violence Against Women of Color, Stanford Law Review, 43 (6): 1241-99

Crocombe, Ron. 2008 The South Pacific. Suva, Fiji: IPS Publications, University of the South Pacific.

Curtin, Jennifer. 2008. "Women, political leadership and substantive representation: The case of New Zealand." Parliamentary Affairs 61 (3): 490-504.

Davidson-Schmich, Louise K. 2011. Gender, Intersectionality, and the Executive Branch: The Case of Angela Merkel, German Politics, 20 (3): 325-41

Deo, Nandini. 2012. "Running from Elections: Indian Feminism and Electoral Politics". Indian Review 11(1): 46-64.

Devlin, Claire, and Robert Elgie. 2008. "The Effect of Increased Women Representation in Parliament: The Case of Rwanda” Parliamentary Affairs 6(2): 237-254.

Dickson-Waiko, Anne. 1999. "Nahau Rooney”. In: Women in Politics: Voices from the Commonwealth. London: Commonwealth Secretariat.

Durose, Catherine, Liz Richardson, Ryan Combs, Christina Eason, and Francesca Gains. 2013. ““Acceptable Difference': Diversity, Representation and Pathways to UK Politics". Parliamentary Affairs 66 (gss085): 246-267.

Durutalo, Alumita. 2012. "Sowing Representative Democracy in the University of the South Pacific Region: Political Party Analysis and Election Observation in the Kingdom of Tonga". Research Report: School of Government, Development and International Affairs. USP, Suva.

Esarey, Justin., \& Chirillo, Gina. 2013. "Fairer Sex” or Purity Myth? Corruption, Gender, and Institutional Context”. Politics \& Gender, 9(4): 361-389. 
Escobar-Lemmon, Maria, and Michelle M. Taylor Robinson. 2005. "Women Ministers in Latin American Government: Where, When, and Why?" American Journal of Political Science 49(4): 829-844.

Fox, Richard L., Jennifer L. Lawless, and Courtney Feeley. 2001. "Gender and the Decision to Run for Office”. Legislative Studies Quarterly 26(3): 411-435.

Fraenkel, Jon. 2006. “The Impact of Electoral Systems on Women's Representation in Pacific Parliaments". Report for the Pacific Islands Forum Secretariat by the Pacific Institute of Advanced Studies in Development \& Governance. Suva: University of the South Pacific.

Hancock, Ange-Marie. 2007. "Intersectionality as a Normative and Empirical Paradigm". Politics \& Gender, 3(2): 248-254.

Hau'ofa, Epeli. 1987. “The New South Pacific Society: Integration and Independence”. In Class and Culture in the Pacific, ed. Antony Hooper et al. Suva and Auckland: Institute of Pacific Studies of the University of the South Pacific and Centre for Pacific Studies of the University of Auckland.

Hixon, Margaret. 2000. Salote: queen of paradise. Dunedin: University of Otago.

Hochrieter, Susanne. 2011. Race, Class, Gender? Intersectionality Troubles. Journal of Research in Gender Studies 1(2): 49-56.

Huffer, Elise. 2006. Desk Review of the Factors Which Enable and Constrain the Advancement of Women's Political Representation in Forum Island Countries. Suva: Pacific Islands Forum Secretariat

Jackson, Keith. 2012. "Loujaya Toni - a life of music, politics and poetry". http://asopa.typepad.com/asopa_people/2012/07/loujaya-toni-a-life-of-music-politicspoetry.html: (February 19, 2013). 
Johnstone, Ian. and Michael Powels. 2012. New Flags Flying: Pacific Leadership. Wellington: Huia Publishers.

Kari, Hilda. 1995 "Solomon Islands Politics: A Personal Reflection”. Paper delivered at the Regional Congress on Gender and Governance. 24 July, Suva.

Kidu, Carol. 2002. A remarkable journey. South Melbourne: Pearson Education Australia. Larmour, Peter. 2012. Interpreting Corruption: Culture and Politics in the Pacific Islands. Honolulu: University of Hawaii Press.

Liki, Asenati. 2010. "Women Leaders in Solomon Islands Public Service: A Personal and Scholarly Reflection." State Society and Governance in Melanesia Discussion Paper (1). Canberra: ANU College of Asia and the Pacific, The Australian National University.

Marsh, Selina. T. 1998. Migrating feminisms: Maligned overstayer or model citizen? Women's Studies International Forum, 21 (6): 665-680

Mohanty, Chandra. 2003. "“Under Western eyes" revisited: feminist solidarity through anticapitalist struggles." Signs 28 (2): 499-535.

Nash, Jennifer. 2008. Re-thinking Intersectionality, Feminist Review 89 (June): $1-15$

Pacific Islands Forum Secretariat. 2012. Pacific Plan Review: Gender and the Regional Agenda. Suva.

Pollard, Alice A. and Marilyn Waring. 2009. Being the first: storis blong oloketa mere lo Solomon Aelan. Honiara, Regional Assistance Mission to Solomon Islands; Auckland, N.Z: AUT University Institute of Public Policy and Pacific Media Centre.

Rai, Shirin. 2012. "The Politics of Access: Narratives of Women MPs in the Indian Parliament”. Political Studies 60(1): 195-212. 
Reeher, Grant. 2006. First Person Political. New York and London: New York University Press.

Ribberink, Anne. 2010. “Gender Politics with Margaret Thatcher: Vulnerability and Toughness". Gender Forum (30): 14-15.

Sawer, Marian. 2013. "Misogyny and Misrepresentation: Women in Australian Parliaments." Political Science 65 (1): 105-117.

Sahlins, Marshall. D. 1963. Poor Man, Rich Man, Big-Man, Chief: Political Types in Melanesia and Polynesia. Comparative Studies in Society and History 5(3): 285-303.

Simms, Marian. 2008. Women's politics and leadership in Australia and New Zealand. Signs: Journal of Women in Culture and Society 34 (1): 32-36

Smooth, Wendy. 2011. "Standing for Women? Which Women? The Substantive Representation of Women's Interests and the Research Imperative of Intersectionality”. Politics \& Gender 7(3): 436-441.

Swami, Nasik. 2014. 'What the politicians say', Fiji Times May 31, pp 16

Underhill-Sem, Yvonne. 2010. Gender, Culture and the Pacific. Asia-Pacific Human Development, Report Background Papers Series, 2010/05, UNDP, Suva

UNIFEM.1998. The Long Road: Pacific Women's Journey to Political Empowerment. Suva, Women in Politic Pacific Centre.

UN Women. 2013. “Advancing Gender Justice in the Pacific Programme Concept Note”, Suva.

Von Wahl, Angelika. 2011. “A ‘women’s revolution from above'? Female leadership, intersectionality, and public policy under the Merkel government”. German Politics 20(3): 392-409. 
Wängnerud, Lena. 2009. "Women in Parliaments: Descriptive and Substantive Representation". Annual Review of Political Science 12(1): 51-69.

Wedega, Alice. 1981. Listen, My Country. Sydney: Pacific Publications.

Whittington, Sherrill, Sofi Ospina, and Alice Aruhe'eta Pollard. 2006. "Women in

Government in Solomon Islands - A Diagnostic Study”.

http://www.cdi.anu.edu.au/.SI/2006-07/D_P/2006_10_SI_diagnostc_study.pdf: (May

2, 2013).

Wood-Ellem, Elizabeth. 1999. Queen Salote of Tonga: the story of an era, 1900-1965.

Auckland: Auckland University Press.

Yanow, Dovra. 2007. “Qualitative-Interpretive Methods in Policy Research”. In Handbook of Policy Analysis: Theory, Politics and Methods, eds. Frank Fischer, Gerald J. Miller and Mara. S. Sidney. Boca Raton, CRC Press: 405-415.

Yuval-Davis, Nira. 2006. "Intersectionality and Feminist Politics." European Journal of Women's Studies 13 (3): 193-209.

\footnotetext{
${ }^{\mathrm{i}}$ So far, only the Autonomous Government of Bougainville has three reserved seats for women in its 39 member parliament. Samoa recently legislated that 10 per cent of parliamentary seats must be reserved for women from the 2016 election.

${ }^{\text {ii }}$ For critical work on intersectionality see Nash (2008).

iii The material presented in this article was collected as part of Jack Corbett's forthcoming (University of Hawaii Press) biographical study of politicians in the Pacific region (in all over 110 interviews and around 40 published life histories with past and present MPs) titled "Being Political: Leadership and Democracy in the Pacific Islands"

${ }^{\text {iv }}$ While we have endeavoured to remain faithful to the integrity of what a politician has said during an interview, clarity and conciseness demanded a degree of editing, with such instances clearly identified using the standard methods. In the case of published life histories, conventional referencing rules have been applied.
} 
${ }^{\mathrm{v}}$ http://www.rnzi.com/pages/news.php?op=read\&id=7053, accessed 19/10/2012. Previously known as Jimmy Rasta, Lusibaea was a key figure in the ethnic tensions of the early 2000 s.

${ }^{\mathrm{vi}}$ Before they even get to an election, due to the perception that female candidates are high-risk, women politicians in Fiji, the Pacific country where two-party politics have historically been strongest, first need to convince the party administration to preselect them in a seat that is winnable. Although, as Crocombe (2008, 468) again highlights, where politicians have been appointed to parliament, in Fiji's Senate for example, the number of women appointees tends to be higher than the number of those elected (this has also been the case in Tonga). 